\title{
Osteochondroma of the Temporomandibular Joint Treated by Means of Condylectomy and Immediate Reconstruction with a Total Stock Prosthesis
}

\author{
Miguel-Angel Morey-Mas ${ }^{1}$, Jorge Caubet-Biayna ${ }^{2}$, José-Ignacio Iriarte-Ortabe ${ }^{1}$ \\ 'Department of Oral and Maxillofacial Surgery, Son Dureta University Hospital, Palma de Mallorca, Spain \\ ${ }^{2}$ Bone regeneration and Oral and Maxillofacial Surgery Unit (GBCOM), Hospital Son Dureta, Insalud, Baleares, Spain
}

\author{
Corresponding Author: \\ Miguel-Angel Morey-Mas \\ Department of Oral and Maxillofacial Surgery \\ Son Dureta University Hospital \\ 55 Andrea Doria Street, 0701 Palma Mallorca \\ Spain \\ Phone: +34971452131 \\ E-mail: mmoreym@gmail.com
}

\begin{abstract}
Background: Osteochondromas are one of the most common benign tumours of bone, but they are rare in the craniofacial region. These condylar tumours have been variably treated, including resection through local excision or condylectomy with or without reconstruction.

Methods: A case of osteochondroma of the mandibular condyle and cranial base arising concurrently in the 76 years old patient was presented. The surgical excision of the skull base lesion and condylectomy with immediate reconstruction of temporomandibular joint was applied.

Results: Based on the history, clinical examination and radiographic findings, osteochondroma of the skull base was diagnosed, with a concurrent lesion of the condylar process. Treatment methods for this patient included excision of the skull base tumour and condylectomy with immediate temporomandibular joint reconstruction using appropriately sized stock total temporomandibular joint prosthesis. At the 24 month follow-up, patient was free of pain and her maximal incisal opening was maintained, with no radiographic evidence of tumour recurrence or failure of the device.

Conclusions: Temporomandibular joint stock total replacement prosthesis became a good option to reconstruct both the fossa and the condyle in a one-stage surgery, due to the fact that both the condylar/mandibular and the fossa implants were stable in situ from the moment of fixation, with a good outcome at 24 month follow-up, with no loosening of the screws nor failure of the device.
\end{abstract}

Keywords: osteochondroma; mandibular neoplasms; mandibular condyle; temporomandibular joint; joint prosthesis implantation.

\footnotetext{
Accepted for publication: 22 October 2010

To cite this article:

Morey-Mas MA, Caubet-Biayna J, Iriarte-Ortabe JI. Osteochondroma of the Temporomandibular Joint Treated by Means of Condylectomy and Immediate Reconstruction with a Total Stock Prosthesis.

J Oral Maxillofac Res 2010 (Oct-Dec);1(4):e4

URL: http://www.ejomr.org/JOMR/archives/2010/4/e4/v1n4e4ht.pdf

doi: $10.5037 /$ jomr.2010.1404
} 


\section{INTRODUCTION}

Osteochondromas are one of the most common benign tumours of bone, representing approximately 35\% to $50 \%$ of all benign tumours and $8 \%$ to $15 \%$ of all primary bone tumours. These tumours are rare in the craniofacial region $(0.6 \%)$ [1], with the coronoid process of the mandible and the mandibular condyle as the most common sites of occurrence [2-4]. When skull base osteochondromas are included, there is a comparable number of case reports mostly located around the temporomandibular joint (TMJ) $[\underline{5}, \underline{6}]$. A relatively high frequency of osteochondromas around the TMJ can be explained embryologically when it is considered that the region from the mandibular lingual to the anterior process of the malleus is derived from the part of Meckel's cartilage not replaced by mandibular bone and that remnants of this embryonic tissue may still persist. But, concurrent osteochondroma involving the mandibular condyle and ipsilateral cranial base is extremely rare, with only one previous case report [7]. The alternative descriptive name of osteocartilaginous exostosis recognizes the uncertainly about the fundamental nature of the lesion. Whether it is in fact developmental, truly neoplastic, or even exuberant repair activity is still controversial [7].

Clinical symptomatology of patients with osteochondromas may include vertical elongation of the face on the affected side with mandibular asymmetry, malocclusion with cross-bite on the contralateral side and lateral open bite on the affected side, TMJ dysfunction symptoms such as pain.

Radiographically, these lesions are radiopaque and are easily identified on computed tomography (CT).

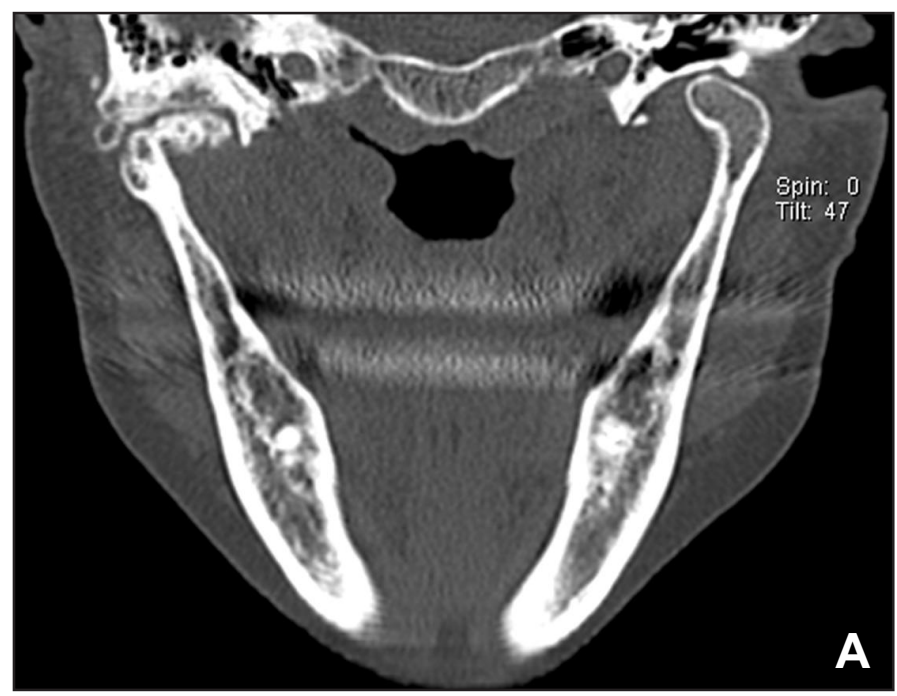

Due to their distinct borders, these tumours can be followed with $\mathrm{CT}$ as well as plain radiography.

These condylar tumours have been variably treated. Treatment has included resection through local excision or condylectomy with or without reconstruction, using a variety of techniques, such as arthroplasty [ $[\underline{8}, 9]$, vertical ramus osteotomy [10], autogenous costochondral graft [11] or total joint prosthesis [7].

In this article, authors present a case of osteochondroma of the mandibular condyle and cranial base arising concurrently in the same patient. The surgical treatment was an excision of the skull base lesion and condylectomy with immediate reconstruction by means of a stock total temporomandibular joint prosthesis.

\section{CASE DESCRIPTION AND RESULTS}

A 76 years old woman was referred to Department of Oral and Maxillofacial Surgery, Son Dureta University Hospital, Palma de Mallorca, Spain for evaluation. She complained of severe right preauricular pain increasing with jaw movement. Patient described it like trigeminal neuralgia. The pain had begun one month before and she had been prescribed anti-inflammatory and musclerelaxing agents only.

Physical examination showed a class I inter-arch relationship, with metal and ceramic dental restoration over implants and teeth. No facial asymmetry, occlusal changes nor preauricular swelling were noticed. A slight limitation $(30 \mathrm{~mm})$ in mouth opening was observed.

The panoramic radiograph showed a shortening of the right condylar neck and a flattening and widening of the right condylar head. The left TMJ was normal. CT showed a severely deformed right condyle with medial

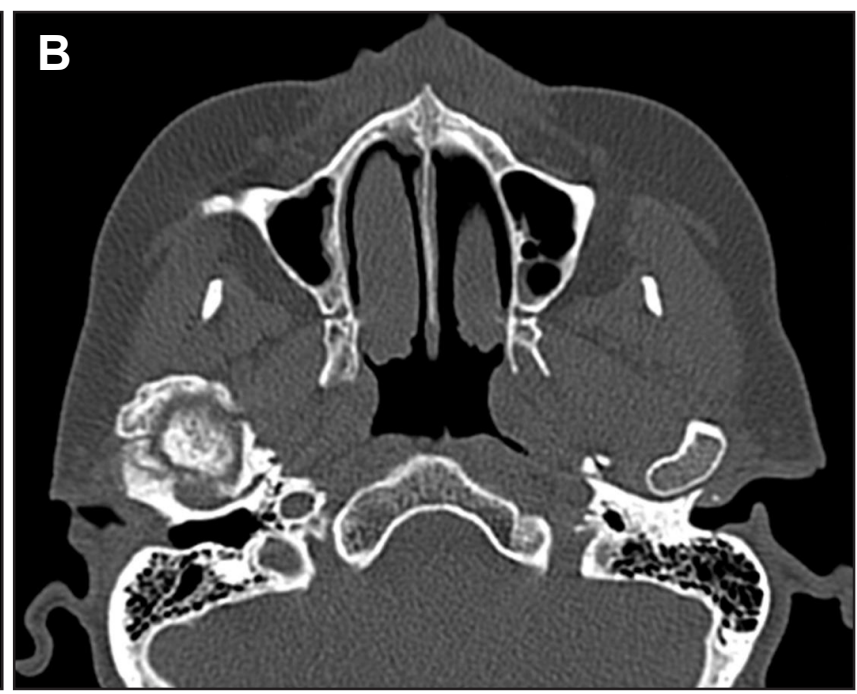

Figure 1. Preoperative patients CT scan.

$\mathrm{A}=$ coronal view showing a deformed right condyle with medial bony projection. The right skull base and fossa are also affected.

$\mathrm{B}=$ axial view with a radiopaque image in the right temporomandibular joint that suggests an osteochondroma. 
bony projections. This was associated with a bony mass at the base of the temporal bone and the articular fossa, with a pseudoarthrosis between the skull base tumour and the deformed condyle (Figure 1 A, B). Due to the proximity to the foramen ovale, the carotid canal and the stylomastoid foramen, magnetic resonance imaging (MRI) was performed to further delineate the anatomy of the tumour and its relationship with the surrounding structures. Neither the CT scan nor the MRI showed any evidence of intracranial extension.

Based on the history, clinical examination and radiographic findings, osteochondroma of the skull base was diagnosed, with possibly a concurrent lesion of the condylar process.

Treatment considerations for this patient included excision of the skull base lesion and condylectomy with delayed or immediate reconstruction. Reconstructive modalities included an autogenous costochondral graft or a total joint prosthesis. A thorough explanation was given to the patient with regard to the risks and benefits of each of the reconstructive modalities. She also was made aware of the fact that completed excision of the lesion at the skull base would not likely be possible because of its relationship to key anatomic structures.

The patient was taken to the operating room and intubated using a fibreoptic nasendoscope. The right TMJ was approached through a preauricular incision. An osseous mass that involved the mandibular condyle and the zygomatic process with a line of demarcation between both structures was exposed (Figure 2). It was excised by means of osteotomies through the condylar neck and the zygoma and, using periosteal elevators, the specimen could be removed in 2 pieces. Further tumour removal at the cranial base using microsurgical techniques was then completed.

Once the tumour was removed, an immediate TMJ reconstruction could be performed, by means of an appropriately sized stock total TMJ prosthesis (Biomet/Lorenz ${ }^{\circledR}$ Warsaw, IN, USA) (Figure 3). The fossa and cranial base were recontoured with a round bur. Then a medium-sized prosthetic fossa was applied to the newly created fossa and, after bony recontouring, was fitted and secured to the lateral aspect of the zygomatic process with six, $2.0 \mathrm{~mm}$ diameter titanium screws. Maxillomandibular fixation (MMF) was placed into her dental occlusion. A submandibular incision was then made, with conventional exposure of the lateral aspect of the ramus. The mandibular component of the prosthesis was sized and a medium extended prosthetic ramus was inserted through the submandibular incision, was properly seated in the fossa and was secured to the ramus with six, $2.7 \mathrm{~mm}$ diameter titanium screws. MMF was released and dental occlusion and prosthetic TMJ movement were checked. All the incisions were

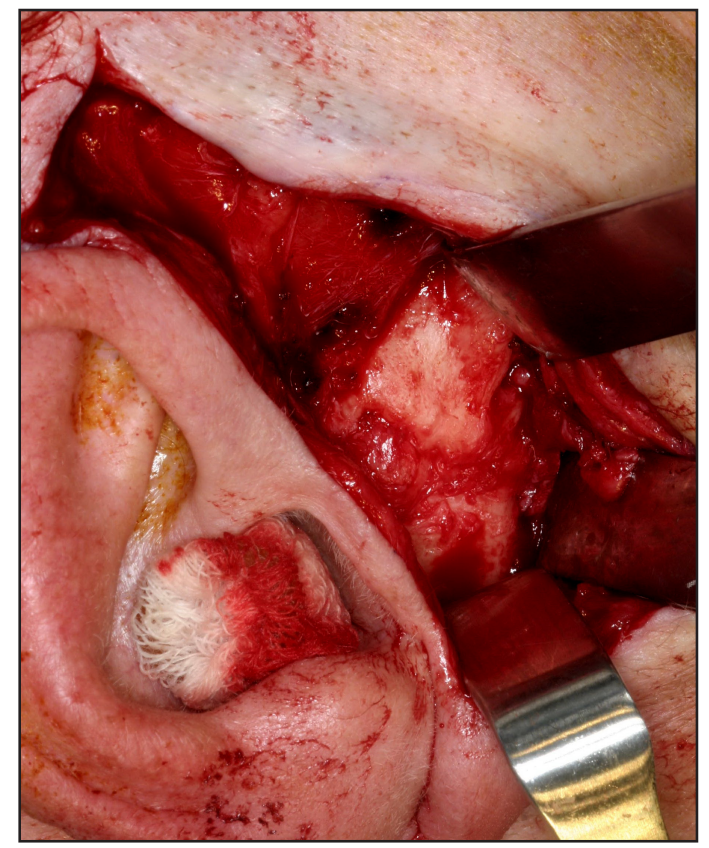

Figure 2. Photograph showing an osseous mass involving the right condyle and the zygoma, with a line of soft tissue between both structures.

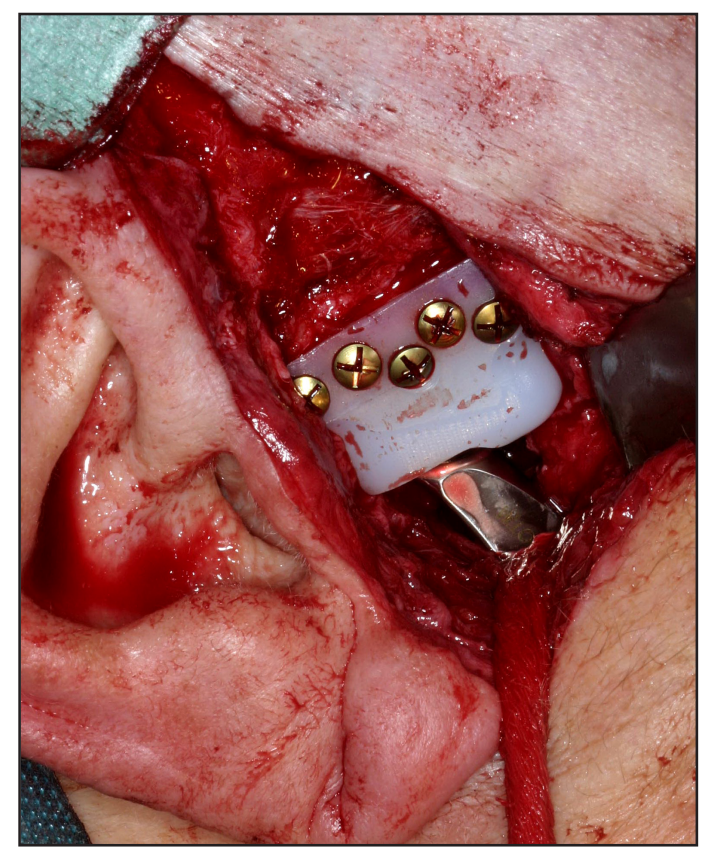

Figure 3. Photograph showing temporomandibular joint fossa and condylar implants fitted in place.

sutured in layers.

The histologic findings confirmed the diagnosis of osteochondroma of the mandibular condyle and skull base.

A week after the intervention, the patient did not experience trigeminal pain and her maximal incisal opening was $30 \mathrm{~mm}$. At the 24 month follow-up, she was free of pain and her maximal incisal opening was maintained, with no radiographic evidence of tumour recurrence or failure of the device (Figure 4). 


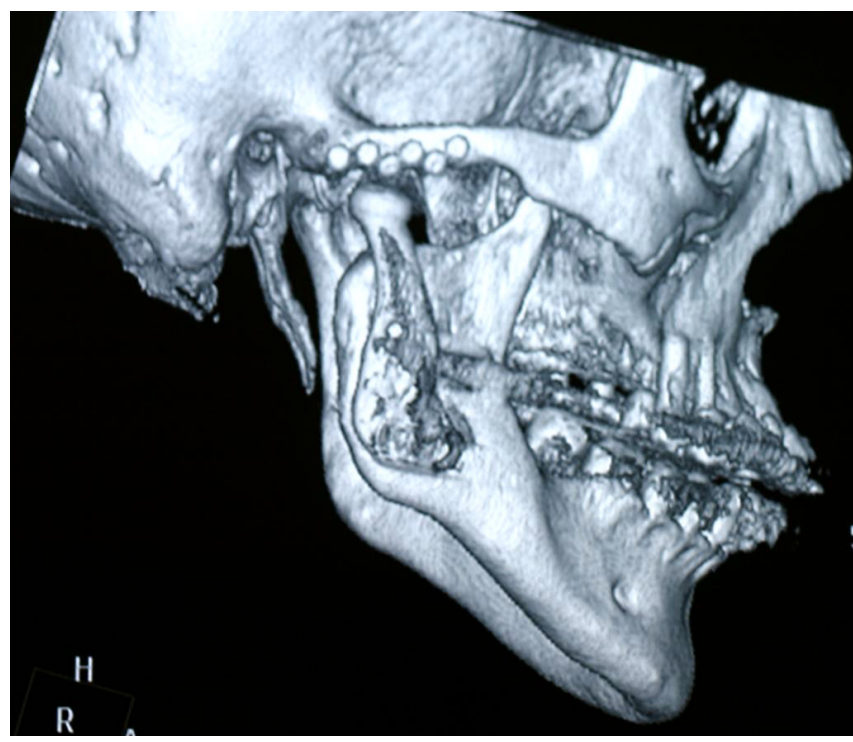

Figure 4. High-resolution CT scan 18 month after operation with computed three-dimensional reconstruction, showing no evidence of tumour recurrence or failure of the device.

\section{DISCUSSION}

Osteochondromas have been characterized as cartilagecapped bony protrusions that present themselves on the external surface of a bone [12]. As a reflection of the combined tissue involvement, this lesion has been named osteocartilaginous exostosis and osteochondroma. Although there are many theories regarding its pathogenesis, it is still uncertain whether the lesion this lesion is developmental, neoplastic or reparative. These theories include the growth of herniated cartilage precursor cells, growth of displaced epiphyseal cartilaginous cells that originated in the metaphysic, hyperplasia of cartilaginous cells due to tensional forces, retained cartilaginous rests that undergo growth or hyperplasia, and tumour cells arising from pleuripotential cells in the periosteum [7].

Although frequently occurring in the axial skeleton, osteochondromas are rare in the maxillofacial region [1]. They have been reported in diverse locations of the craniofacial area that include the zygoma [13], maxillary sinus [14], the skull base [5], the glenoid fossa and mandible [6], where the most common sites are the coronoid process and the condyle [2-4]. Mandibular osteochondroma has also been reported to occur in the ramus, body, angle and symphyseal regions, however, concurrent osteochondroma involving the skull base and the ipsilateral condyle is extremely rare, with only one previous case report [7].

Typical facial features of condylar osteochondromas include facial asymmetry, malocclusion with open-bite on the affected side, and/or prognathic deviation of the chin and cross-bite to the contralateral side. Mouth opening is in normal range in most of the cases because of the pseudoarticulation around the mass. When the facial asymmetry is not noticeable, these tumours are usually diagnosed as TMJ dysfunctions, been pain the predominant symptom in these patients [9].

Radiographically, on plain films, these tumours can appear as exophytic masses with mixed density and a sclerotic appearance. CT and MRI examination are mandatory in evaluating cases of large tumours, with possible involvement of cranial or vascular structures. Histologically, these lesions are composed of wellcircumscribed bone and cartilaginous cap. Underlying the cartilaginous cap is the bony component, which may also have proliferating chondrocytes overlying bone that resembles the condyle as it undergoes endrochondral ossification [6].

The recurrence rate for solitary osteochondromas in long bones is approximately $2 \%$, and there is only one recurrence of a condylar osteochondroma reported in the literature, which occurred a year after its excision in multiple pieces [9].

Solitary osteochondromas have a $1 \%$ risk of malignant transformation [9]. Skull base osteochondroma has been reported to undergo sarcomatous degeneration; however, this is an extremely rare occurrence [7].

The treatment protocol for these condylar tumours is controversial. Local resection or conservative condylectomy with recontouring of the residual condylar neck and repositioning of the articular disc is a viable option for treatment of osteochondromas that involve the head of the condyle, without the extension of tumour into the neck $[\underline{8}, \underline{9}]$. Another acceptable reconstructive procedure for condylar lesions where the ramus is not involved could be superiorly moving the posterior ramus border by ramus osteotomy, reconstructing a neocondyle with satisfactory TMJ function, thus avoiding a donor site deformity [10]. In cases of osteochondroma where the condylar head and neck require removal, a total condylectomy and simultaneous joint reconstruction is recommended by most surgeons, due to the benign nature of these lesions, the low likelihood of recurrence and the importance of the ramus height in TMJ function $[\underline{7}, \underline{8}]$. At present, autogenous bone grafts (costochondral or sternoclavicular grafts) are frequently considered for condylar reconstruction, but carries inevitable disadvantages, such as donor site morbidity, exploration of two surgical sites and bone resorption $[\underline{11}, \underline{16}, \underline{17}]$. Total joint prosthesis is another alternative of TMJ reconstruction, especially when both condyle and fossa have to be reconstructed after tumour resection [7]. Several papers have reported that TMJ alloplastic replacement is a safe, effective and reliable option in severely degenerate joints, with predictable outcomes and an improvement in the quality of life in these 
patients [18-21]. Some advantages of alloplastic joint reconstruction are: 1) that the physical therapy can start immediately after implantation, 2) a secondary donor site is obviated, and thus surgery time and potential morbidity are reduced, and 3) the TMJ's anatomy and function can be mimicked. Disadvantages include: 1) the cost of the device, 2) material wear and potential failure, and 3) restricted use in the growing patient $[20,21]$.

Customized prosthetic systems are frequently designed and manufactured for each specific situation. This ensures intimate contact between the host bone and the device, thus decreasing micromotion under functional loading which may lead to loosening of the fixation and premature failure of the prosthesis [22]. The alternative use of a stock prosthetic system, which is provided in different sizes and shapes for both the condylar/ mandibular and the fossa components, allows adaptation of the host bone to the implants [23]. In theses stock systems are not necessary a previous design of their components, and they are indicated for immediate TMJ reconstruction in not planned cases. On the other hand, the manufacture of custom devices needs a presurgical work-up, where an accurate three-dimensional plastic model of the patient's joints is constructed from CT data. The prostheses are manufactured from this model with this process taking $6-8$ weeks. In the present case, due to the severity of pain, the patient refused to wait for this period of time. She also rejected a two-stage procedure, consisting of a tumour resection with a delayed reconstruction.

\section{CONCLUSIONS}

Under these considerations, a Biomet/Lorenz ${ }^{\circledR}$ stock prosthesis became a good option to reconstruct both the fossa and the condyle in a one-stage surgery, due to the fact that both the condylar/mandibular and the fossa implants were stable in situ from the moment of fixation, with a good outcome at 24 month follow-up, with no loosening of the screws nor failure of the device.

\section{ACKNOWLEDGMENTS AND DISCLOSURE STATEMENTS}

Dr. Miguel Angel Morey-Mas is a Surgeon Consultant for Biomet Microfixation, LLC.

\section{REFERENCES}

1. Khurana J, Abdul-Karim F, JBoevo VMG. Osteochondroma. In: Mirra JM, Picci P, Gold RH, editors. Bone Tumors: Clinical, Radiological and Pathological Correlations. Philadelphia, Pa: Lea and Febiger; 1989. p. 234-237.

2. Kerscher A, Piette E, Tideman H, Wu PC. Osteochondroma of the coronoid process of the mandible. Report of a case and review of the literature. Oral Surg Oral Med Oral Pathol. 1993 May;75(5):559-64. Review. [Medline: 8488021] [doi: 10.1016/0030-4220(93)90224-R]

3. Goyal M, Sidhu SS. A massive osteochondroma of the mandibular condyle. Br J Oral Maxillofac Surg. 1992 Feb;30(1):66-8. [Medline: 1550810] [doi: 10.1016/0266-4356(92)90141-5]

4. Kurita K, Ogi N, Echiverre NV, Yoshida K. Osteochondroma of the mandibular condyle. A case report. Int J Oral Maxillofac Surg. 1999 Oct;28(5):380-2. Review. [Medline: 10535542] [doi: 10.1016/S0901-5027(99)80088-5]

5. Castillo M, Hudgins PA, Hoffman JC Jr. Lockjaw secondary to skull base osteochondroma: CT findings. J Comput Assist Tomogr. 1989 Mar-Apr;13(2):338-9. [Medline: 2925926] [doi: 10.1097/00004728-198903000-00031]

6. Buoncristiani RD, Casagrande A, Felsenfeld AL. Osteochondroma of the glenoid fossa: occurrence in an atypical location. J Oral Maxillofac Surg. 2003 Jan;61(1):134-7. [Medline: 12524622] [doi: 10.1053/joms.2003.50023]

7. Karras SC, Wolford LM, Cottrell DA. Concurrent osteochondroma of the mandibular condyle and ipsilateral cranial base resulting in temperomandibular joint ankylosis: report of a case and review of the literature. J Oral Maxillofac Surg. 1996 May;54(5):640-6. Review. [Medline: 8632254] [doi: 10.1016/S0278-2391(96)90652-7]

8. Wolford LM, Mehra P, Franco P. Use of conservative condylectomy for treatment of osteochondroma of the mandibular condyle. J Oral Maxillofac Surg. 2002 Mar;60(3):262-8. [Medline: 11887135] [doi: 10.1053/joms.2002.30570]

9. Aydin MA, Küçükçelebi A, Sayilkan S, Celebioğlu S. Osteochondroma of the mandibular condyle: report of 2 cases treated with conservative surgery. J Oral Maxillofac Surg. 2001 Sep;59(9):1082-9. Review. [Medline: 11526583]

10. Song D, Zhu S, Hu J, Li J, Luo E. Use of ramus osteotomy for the treatment of osteochondroma in the mandibular condyle. J Oral Maxillofac Surg. 2009 Mar;67(3):676-80. [Medline: 19231801] [doi: 10.1016/j.joms.2008.07.018]

11. Saeed NR, Kent JN. A retrospective study of the costochondral graft in TMJ reconstruction. Int J Oral Maxillofac Surg. 2003 Dec;32(6):606-9. [Medline: 14636610] [doi: 10.1054/ijom.2003.0418]

12. Schajowicz F, Ackerman LV, Sissons HA. International Histological Classification of Tumours No 6: Histological Typing of Bone Tumours. Geneva, Switzerland, World Health Organization, 1972. 
13. Pool JW, Tilson HB, Thornton WE, Steed DL. Osteochondroma of the zygomatic arch: report of case. J Oral Surg. 1979 Sep;37(9):673-5. [Medline: 288891]

14. Traub DJ, Marco WP, Eisenberg E, Barrows G. Osteochondroma of the maxillary sinus: report of a case. J Oral Maxillofac Surg. 1990 Jul;48(7):752-5. [Medline: 2358955] [doi: 10.1016/0278-2391(90)90066-B]

15. Navez JL, Lechien P, Van Craynest MP, Maldague P. [Osteochondroma of the mandible]. Acta Stomatol Belg. 1982;79(1):13-23. French. [Medline: 6954838]

16. MacIntosh RB. The use of autogenous tissues for temporomandibular joint reconstruction. J Oral Maxillofac Surg. 2000 Jan;58(1):63-9. Review. [Medline: 10632167] [doi: 10.1016/S0278-2391(00)80019-1]

17. Wolford LM, Cottrell DA, Henry C. Sternoclavicular grafts for temporomandibular joint reconstruction. J Oral Maxillofac Surg. 1994 Feb;52(2):119-28; discussion 128-9. [Medline: 8295045 ] [doi: 10.1016/0278-2391(94)90391-3]

18. Wolford LM, Pitta MC, Reiche-Fischel O, Franco PF. TMJ Concepts/Techmedica custom-made TMJ total joint prosthesis: 5-year follow-up study. Int J Oral Maxillofac Surg. 2003 Jun;32(3):268-74. [Medline: 12767873] [doi: 10.1054/ijom.2002.0350]

19. Mercuri LG. Subjective and objective outcomes in patients reconstructed with a custom-fitted alloplastic temporomandibular joint prosthesis. J Oral Maxillofac Surg. 1999 Dec;57(12):1427-30. [Medline: 10596663] [doi: 10.1016/S0278-2391(99)90725-5]

20. Mercuri LG. The use of alloplastic prostheses for temporomandibular joint reconstruction. J Oral Maxillofac Surg. 2000 Jan;58(1):70-5. Review. [Medline: 10632168] [doi: 10.1016/S0278-2391(00)80020-8]

21. Mercuri LG, Edibam NR, Giobbie-Hurder A. Fourteen-year follow-up of a patient-fitted total temporomandibular joint reconstruction system. J Oral Maxillofac Surg. 2007 Jun;65(6):1140-8. [Medline: 17517298] [doi: 10.1016/i.joms.2006.10.006]

22. Mercuri LG, Wolford LM, Sanders B, White RD, Giobbie-Hurder A. Long-term follow-up of the CAD/CAM patient fitted total temporomandibular joint reconstruction system. J Oral Maxillofac Surg. 2002 Dec;60(12):1440-8. [Medline: 12465008] [doi: 10.1053/joms.2002.36103]

23. Guarda-Nardini L, Manfredini D, Ferronato G. Temporomandibular joint total replacement prosthesis: current knowledge and considerations for the future. Int J Oral Maxillofac Surg. 2008 Feb;37(2):103-10. Epub 2007 Nov 19. Review. [Medline: 18022347] [doi: 10.1016/j.ijom.2007.09.175]

\section{To cite this article:}

Morey-Mas MA, Caubet-Biayna J, Iriarte-Ortabe JI. Osteochondroma of the Temporomandibular Joint Treated by Means of Condylectomy and Immediate Reconstruction with a Total Stock Prosthesis.

J Oral Maxillofac Res 2010 (Oct-Dec);1(4):e4

URL: http://www.ejomr.org/JOMR/archives/2010/4/e4/v1n4e4ht.pdf

doi: $10.5037 /$ jomr.2010.1404

Copyright ( $\odot$ Morey-Mas MA, Caubet-Biayna J, Iriarte-Ortabe JI. A. Accepted for publication in the JOURNAL OF ORAL \& MAXILLOFACIAL RESEARCH (http://www.ejomr.org/), 22 October 2010.

This is an open-access article, first published in the JOURNAL OF ORAL \& MAXILLOFACIAL RESEARCH, distributed under the terms of the Creative Commons Attribution-Noncommercial-No Derivative Works 3.0 Unported License, which permits unrestricted non-commercial use, distribution, and reproduction in any medium, provided the original work and is properly cited. The copyright, license information and link to the original publication on (http://www.ejomr.org/) must be included. 